\title{
Three Cs of Translating Evidence-Based Programs for Youth and Families to Practice Settings
}

Kimberley E. Freire, Leah Perkinson, Susan Morrel-Samuels, Marc A. Zimmerman

\begin{abstract}
Despite the growing number of evidence-based programs (EBPs) for youth and families, few are well-integrated in service systems or widely adopted by communities. One set of challenges to widespread adoption of EBPs relates to the transfer of programs from research and development to practice settings. This is often because program developers have limited guidance on how to prepare their programs for broad dissemination in practice settings. We describe Three Cs of Translation, which are key areas that are essential for developers to translate their EBPs from research to practice settings: (1) Communicate the underlying theory in terms easily understandable to end users, (2) Clarify fidelity and flexibility, and (3) Codify implementation lessons and examples. Program developers are in the best position to describe their interventions, to define intervention core components, to clarify fidelity and flexibility, and to codify implementation lessons from intervention studies. We note several advantages for developers to apply the Three Cs prior to intervention dissemination and provide specific recommendations for translation. (c) 2015 Wiley Periodicals, Inc.
\end{abstract}

The findings and conclusions in this article are those of the authors and do not necessarily represent the official position of the Centers for Disease Control and Prevention. 


\section{Introduction}

$\mathrm{F}$ ederal initiatives for children and adolescents include a broad array of programs, services, policies, and practices, often implemented in complex systems or communities. Since the 1990s, evidence movements in a variety of fields (Brownson, Fielding, \& Maylahn, 2009; Davies, 1999; Sackett, Rosenberg, Gray, Haynes \& Richardson, 1996) have resulted in more standardized packaged programs for youth that have been evaluated and that have demonstrated promise for improving health and social outcomes. Today, practitioners can access several registries of evidence-based programs (EBPs) that rate programs based on specific criteria of evidence (Center for the Study and Prevention of Violence, n.d.; Centers for Disease Control and Prevention [CDC], 2014, 2015; Substance Abuse and Mental Health Services Administration [SAMHSA], 2015; U.S. Department of Health and Human Services [HHS] Office of Adolescent Health, 2015). This article focuses on three key areas in which program developers can help prepare their programs for registries and ultimately for widespread use and adoption in practice settings.

Despite the growing number of EBPs for youth and their families, few programs are well integrated in service systems or widely adopted by communities (Backer \& Guerra, 2011; Collins et al., 2012; Fixsen, Naoom, Blase, Friedman, \& Wallace, 2005; Kilbourne, Neumann, Pincus, Bauer, \& Stall, 2007; Paulsell, Del Grosso, \& Supplee, 2014). One set of challenges to widespread adoption of EBPs relates to the transfer of programs from research and development to practice settings (Fixsen et al., 2005; Halle, Metz, \& Martinez-Beck, 2013; Kilbourne et al., 2007). Many youth-focused programs are rooted in complex theories of change that link behavioral and ecological concepts to program activities and outcomes. These programs often assume synergy between program content delivered and the implementation environment, which includes implementers, participants, and characteristics of program settings. Practice contexts, however, typically differ from the initial contexts in which programs were evaluated. In addition, practitioners often lack information on how a program's theory maps onto its activities, or the developer's intentions for implementation to achieve the spirit of the program (Steckler \& Linnan, 2002). Many implementers, therefore, may be unaware of the theories underlying EBPs and how they connect to program content and delivery. As a result, program implementers may make changes to a program to fit their contexts without a clear understanding of how changes may impact the program's desired outcomes.

Program developers often have limited guidance on how to prepare their programs for broad dissemination in practice settings. Prevalent research to practice translation models describe processes for dissemination (Glasgow, Lichtenstein, \& Marcus, 2002; Wandersman et al., 2008; Wilson, Brady, \& Lesesne, 2011; Woolf, 2008), but typically do not provide developers with specific recommendations for communicating their rationale for program components and intentions for implementation in terms that 
practitioners can easily understand and apply to their context. One notable exception is the Replicating Effective Programs (REP) program, which was developed by the CDC to translate efficacious human immunodeficiency virus (HIV) behavioral prevention interventions for dissemination in community-based settings (Eke, Neumann, Wilkes, \& Jones, 2006). REP uses four phases to package, tailor, implement, and evaluate EBPs and provides recommendations for researchers (developers) on translating program materials and identifying implementation lessons.

This article distills major lessons from previous program dissemination work and highlights key actions developers can take prior to the packaging and dissemination of their programs. We recognize that these actions are only a small (but essential) part of program dissemination. In the sections that follow, we describe what we call Three Cs of Translation, for developers to transition their EBPs from research to practice settings. Specifically, we describe how developers can Communicate the underlying theory of their programs in terms that are easily understandable to end users, Clarify fidelity and flexibility, and Codify implementation lessons and examples (see Table 3.1). For each of the Three Cs, we define key concepts, describe developer challenges, and make recommendations for translating EBPs from research to practice settings.

Communicate the Intervention's Underlying Theory in Terms Easily Understandable to the End User. A theory of change (TOC) describes the hypothesized cause and effect relationships among a program's components and short- and long-term outcomes or its underlying logic (Glanz, Rimer, \& Viswanath, 2008). Developers commonly use a TOC to communicate research hypotheses tested in an intervention study, and as such, most EBPs have a well-defined TOC that illustrates pathways from program activities to short- and long-term outcomes. However, TOC models often do not explain what the developer considers to be the program's active ingredients or the synergy between what is delivered, how it is delivered, and who delivers it.

Active ingredients, or core components, refer to a program's underlying logic in terms of how a program is intended to function and which program components are likely responsible for program effects (Backer, 2002; Blase \& Fixsen, 2013; Galbraith et al., 2011; Kelly, Heckman, Stevenson, \& Williams, 2000; McKleroy et al., 2006). Program core components can be operationalized as program content (what), delivery (how), and implementer characteristics (who) that are intended to work together to achieve desired outcomes. Content refers to knowledge, skills, and messages delivered through program activities. Delivery refers to instructional methods (pedagogy), implementation context, timing, ordering, and logistics. Some developers have referred to delivery as the program method (Hansen et al., 2013), while others have distinguished core pedagogy and core implementation characteristics as separate constructs (Galbraith et al., 2011). Implementer refers to the characteristics of the persons and organizations 
Table 3.1. Three Cs of Translation

\begin{tabular}{|c|c|c|}
\hline Developer's Role & Translation Purpose & Recommendations for Developers \\
\hline $\begin{array}{l}\text { Communicate } \\
\text { underlying } \\
\text { theory }\end{array}$ & $\begin{array}{l}\text { Define core components in } \\
\text { concrete terms guided } \\
\text { by content, delivery, and } \\
\text { implementer and link } \\
\text { components with } \\
\text { program activities. }\end{array}$ & $\begin{array}{l}\text { Specify core content, delivery, } \\
\text { and implementer components } \\
\text { Indicate in which program } \\
\text { activities core components are } \\
\text { prominent } \\
\text { Describe link between specific } \\
\text { activities or components and } \\
\text { outcomes }\end{array}$ \\
\hline $\begin{array}{l}\text { Clarify fidelity and } \\
\text { flexibility }\end{array}$ & $\begin{array}{l}\text { Define fidelity in terms of } \\
\text { core components and } \\
\text { specific adaptations that } \\
\text { are not likely to } \\
\text { compromise core } \\
\text { components. }\end{array}$ & $\begin{array}{l}\text { Describe fidelity in terms of core } \\
\text { components } \\
\text { Describe what full } \\
\text { implementation looks like } \\
\text { Link fidelity checklists and } \\
\text { observation forms to core } \\
\text { content and delivery } \\
\text { Indicate options for flexibility } \\
\text { (adaptations) that maintain } \\
\text { core components }\end{array}$ \\
\hline $\begin{array}{l}\text { Codify } \\
\text { implementation } \\
\text { lessons and } \\
\text { training }\end{array}$ & $\begin{array}{l}\text { Use implementation } \\
\text { lessons to identify } \\
\text { challenges that influence } \\
\text { implementation quality } \\
\text { and identify examples of } \\
\text { good implementation } \\
\text { practices that maintain } \\
\text { core components. }\end{array}$ & $\begin{array}{l}\text { Detail technical assistance } \\
\text { provided at different points } \\
\text { during implementation } \\
\text { Describe contextual factors that } \\
\text { influenced implementation } \\
\text { Describe common adaptations } \\
\text { that improved implementation } \\
\text { while maintaining core } \\
\text { components } \\
\text { Provide examples of high-quality } \\
\text { implementation }\end{array}$ \\
\hline
\end{tabular}

delivering program activities, including but not limited to essential skills, previous implementation experiences, and comfort level with intervention content (Blase \& Fixsen, 2013; Galbraith et al., 2011). Many programs that engage youth and families rely on the relationships between implementers and participants as an essential part of how the program functions (Aarons, Miller, Green, Perrott, \& Bradway, 2012). Coaching Boys Into Men (CBIM), for example, is a dating violence prevention program that trains high school sports coaches to deliver weekly violence prevention messages and facilitate team discussions (Miller et al., 2012, 2013). CBIM relies on coaches' existing relationships with their athletes to engage program participants and influence how they receive program messages. Jaime et al. (2015) found that one reason a domestic violence advocate was able to deliver CBIM effectively was that he built relationships with athletes through sports (i.e., workouts before practice) prior to and during program implementation. In another example, a process evaluation of the Youth Empowerment Solutions (YES) program (Franzen, Morrel-Samuels, Reischl, \& Zimmerman, 2009) revealed participants' preferences for younger implementers, in part 
because participants felt they were able to relate to implementers closer to their age.

Clarify Fidelity and Flexibility in Terms of Core Components. Developers define program fidelity in different ways, but they generally agree that fidelity means that a program is implemented in a way that is consistent with the underlying program theory and reflects the developer's intentions (Backer, 2002; Dane \& Schneider, 1998; Durlak \& DuPre, 2008; Dusenbury, Brannigan, Hansen, Walsh, \& Falco, 2005; Hansen et al., 2013). Dane and Schneider (1998) further specify fidelity within five domains, including adherence, dose, quality of delivery, participant responsiveness, and program differentiation. Other developers define fidelity in terms of adherence to a program's core components, which assumes that developers have defined these components (Backer, 2002; Blase \& Fixsen, 2013; Hansen et al., 2013).

One challenge for practitioners implementing EBPs is understanding what a high level of fidelity looks like in practice. In our experience with practitioners implementing EBPs, implementers often understand the concept of fidelity as something you either have or do not have and something you can only have if you change nothing. This understanding may reflect a missing link between how developers generally define fidelity and how they would operationalize fidelity in practice.

Flexibility refers to elements of a program that can be modified or enhanced without compromising the core components (Backer, 2002; Hansen et al., 2013; Mazzucchelli \& Sanders, 2010). This is commonly referred to as adaptation. Adaptation refers to a broad range of modifications, including minor adjustments or surface-level changes and enhancements, major modifications, or deep-level changes (Resnicow, Soler, Braithwaite, Ahluwalia, \& Butler, 2000; SAMHSA, 2015) and program drift (SAMHSA, 2015). Rogers (1995) also refers to re-invention, defined as the extent to which programs are modified by users during adoption and implementation. Many researchers have documented adaptations to youth and parent programs implemented in practice settings (Aarons et al., 2012; Blakely et al., 1987; Dusenbury et al., 2005; Hansen et al., 2013; McGraw et al., 1996; Moore, Bumbarger, \& Rhoades Cooper, 2013; Ozer, Wanis, \& Bazell, 2010; Ringwalt, Ennett, Vincus, \& Simons-Rudolph, 2004). Aarons and colleagues (2012), for example, found that facilitators implementing the Incredible Years Basic Parent Program made adaptations to program content and delivery in response to organizational factors, participant needs, and facilitators' beliefs about how to best engage parents. A common adaptation, for example, was facilitators' change to the delivery format from one large group (as designed) to small groups to foster facilitators' relationship with participants (Aarons et al., 2012). Researchers studying various programs implemented in schools have documented adaptations to curricula due to logistical constraints, student engagement, and classroom management issues (Blakely et al., 1987; Dusenbury et al., 2005; 
Hansen et al., 2013; McGraw et al., 1996; Ozer et al., 2010; Ringwalt et al., 2004). In other research, Moore and colleagues (2013) found that agencies implementing 10 different EBPs with children and families made adaptations prior to implementation to address program fit with their agencies' philosophy, as well as during implementation to address participant needs and logistical constraints.

Codify Implementation Lessons and Implementation Examples. Codifying implementation lessons assumes that developers systematically document implementation challenges and adjustments during evaluation studies and early implementations in practice settings (Eke et al., 2006). Implementation lessons could be categorized under core components related to content, delivery, and implementer characteristics, as well as contextual factors that influenced implementation. In a study of the implementation of the Positive Parenting Program (Triple P; Prinz, Sanders, Shapiro, Whitaker, \& Lutzker, 2009; Sanders, 1999), implementers reported that some parents did not understand certain concepts related to positive parenting (Freire, Perkinson, Romney, \& Lippy, 2015). One session in Triple P, for example, focuses on how parents can provide praise to children for positive behaviors. In some cases, parents are from cultural groups that do not have praise as a relevant parenting concept or did not experience praise as a child. To address parent needs related to this content, implementers clarified what was meant by praise in terms acceptable to parents (i.e., praise the behavior not the child), reviewed homework practices with parents in class, and engaged parents in role-play activities so that they could implement effectively what the developers termed praise in their original materials. These types of translations maintain the gist of the active ingredients but are not typically documented in a systematic fashion to benefit future implementers who come across similar issues.

\section{Challenges and Recommendations for Developers}

For each of the Three Cs, we describe developer challenges and make recommendations for developers.

Communicating the Program's Underlying Theory. Developers are sometimes reluctant to label a program component as core (or fundamental) without empirical support even if the underlying theory might suggest it (Blase \& Fixsen, 2013; Galbraith et al., 2011; Moore et al., 2013). Many evaluators only test the overall effect of a program and do not include program component analyses. Nonetheless, identifying core components may have the greatest promise for developers to communicate their intentions and rationale for implementing program activities.

A pragmatic approach to identifying core components uses the best available and different types of evidence to specify which active ingredients likely drive program effects, while recognizing limitations inherent in each method. In addition to systematic components analyses, other methods for establishing core program components include the following: 
using the program's TOC and social and behavioral theory more broadly; synthesizing implementation and adaptation data collected during intervention studies (Galbraith et al., 2011); collecting qualitative data from the development team, implementers, and participants (Kelly et al., 2000; Kirby, Laris, \& Rolleri, 2006; Mowbray, Holter, Teague, \& Bybee, 2003); and conducting usability testing after an evaluation study and before widespread implementation (Blase \& Fixsen, 2013).

Once core components are defined, developers can link components to specific program activities and explain their intent for delivery. The translation from conceptual to practical application is often the missing link in program implementation materials. This can be done by mapping core content components to specific program sessions, articulating the modes of delivery, and defining ideal implementer characteristics. This mapping exercise more clearly delineates how core components operate and provides an explicit rationale for implementing activities as intended. Youth Empowerment Solutions for Positive Youth Development (YES), for example, is a promising youth violence prevention program based on empowerment and ecological theories (Reischl et al., 2011; Zimmerman, Stewart, Morrel-Samuels, Franzen, \& Reischl, 2011). YES is designed for middle school-aged youth and promotes youth leadership and positive community engagement. Table 3.2 includes excerpts from the YES program core components document (Morrel-Samuels, Hutchison, Perkinson, Bostic, \& Zimmerman, 2014) to illustrate how the developer communicated the program's underlying theory as core content, delivery, and implementer characteristics. To identify core components, developers first operationalized each of the three constructs of empowerment theory that are the foundation for the program's theory of change: intrapersonal (feeling), interactional (connecting), and behavioral (doing). The behavioral construct of empowerment theory, for example, is described in lay terms as doing, which is operationalized by three types of behaviors: leadership, community, and school engagement. Next, developers linked key content (e.g., messages and skills) to each program session and activities within sessions to help implementers understand how program content and activities are intended to influence the three key behaviors. The document also described core delivery components and implementer characteristics that reflect the developer's intention for how content should be delivered. Core delivery components include delivery modes and supports that help to create a safe and empowering environment for youth. Core implementer components include, for example, group and neighborhood leaders' ability to engage youth to lead. Staff from four health departments implementing YES provided feedback prior to implementation and again after they had started implementing the program. The developers then refined the core components document based on feedback about clarity and usability.

Clarifying Fidelity and Flexibility. Fidelity checklists that are commonly packaged with program implementation materials often reflect 


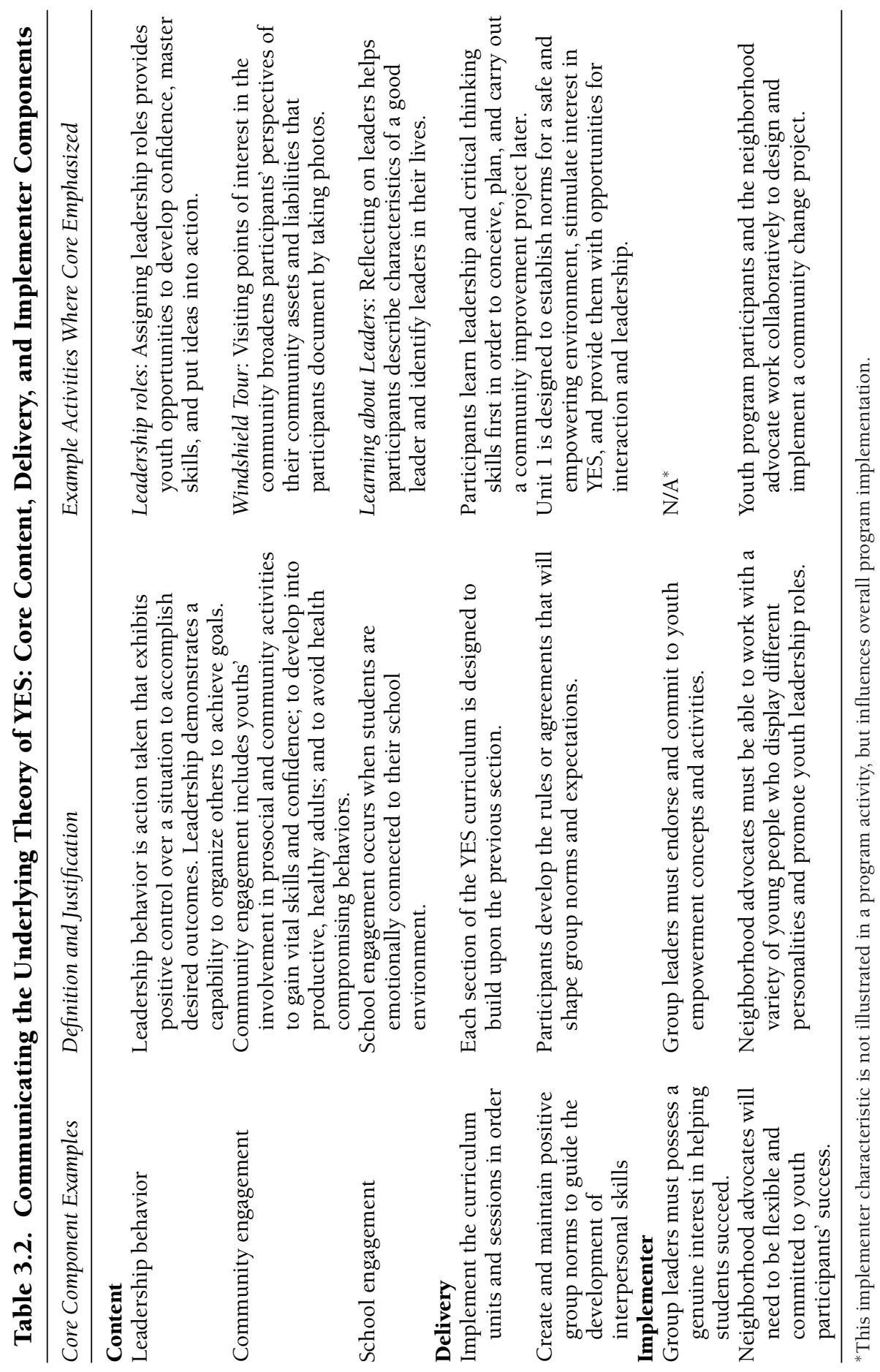


whether program activities were covered, but not whether they were delivered in a manner consistent with the program core components. Three ways to apply fidelity and flexibility to program components are as follows: (1) describe fidelity in terms of core components; (2) develop or modify existing fidelity checklists and observation forms to reflect content, delivery, and implementer core components; and (3) develop adaptation guidance that at a minimum describes how core components should be maintained when making changes.

Returning to the YES example, before the program developers identified core components, fidelity monitoring tools for practitioners were primarily implementation logs where practitioners could record certain elements of fidelity, such as percentage of the activity completed and percentage of youth engaged in a specific activity. The log provided space for implementers to record their reflections about the activities and how the activity could be improved. Although the implementer log captured dosage, it did not allow practitioners to assess the extent to which implementation was consistent with core content, delivery, and implementer components. Some activities, for example, could be technically delivered in full, but lack facilitator prompts for youth participants to initiate questions and discussion to process content. After identifying core components, developers created session-specific observation forms based on previous published guides that were available to practitioners (Hansen, Pankratz, \& Bishop, 2014). Each observation form includes checkboxes to indicate whether an activity was completed, as well as space for the observer to note any changes to content or delivery. Forms also operationalize desired implementer characteristics, such as promoting youth leadership during activities, as well as high-quality delivery through a checklist of items (e.g., implementer checked in with youth to ensure that they understood concepts and focused discussion on main messages).

Program adaptation guidance often is developed after implementation begins, in response to real-world implementation challenges. In our experience working with program developers, they sometimes do not create adaptation guidance as part of an implementation package due to their beliefs that such guidance may promote the idea that adaptations are necessary, acceptable, and encouraged. In the absence of developer-led guidance, however, stakeholders involved in EBP implementation are left to define their own rules.

Operationalizing flexibility and allowable adaptations in terms of core components can provide practitioners with guideposts to make adaptations that are congruent with a program's underlying theory and the developers' intent. YES developers created adaptation guidance that integrated the program's defined core components into a step-by-step process that served to aid implementers in making decisions about potential adaptations to the curriculum to improve YES program fit with their local context 
(Morrel-Samuels et al., 2014). The guide walks implementers through the process of assessing their organization's readiness to implement YES, understanding the relationship of the core components to curriculum activities, describing various types and reasons for adaptations and their likely effects on core components, and developing adaptations that are consistent with the YES core components.

Codifying Implementation Lessons. Peer-reviewed journals emphasize reports of intervention outcomes, and lessons from the implementation process are often not well documented in published literature. Yet, descriptions of implementation lessons and real-world examples of implementation, in our experience, are the most concrete ways to communicate what a program looks like in practice. Documenting implementation lessons and integrating them with program materials may be particularly useful to practitioners in the following three areas: (1) pointing to implementation challenges and solutions in training materials and technical assistance guidance, (2) identifying examples of adaptations that did not compromise core components in implementation and adaptation guidance, and (3) identifying exemplars of what quality implementation looks like (Eke et al., 2006; Jones, Baker, Gelaude, King, \& Jemmott, 2013; Wilkes et al., 2014).

Returning to the example of four health departments that implemented YES, over the course of nine months YES developers tracked the technical assistance requests they received and reviewed implementation data submitted by health departments, which described implementers' adaptations, reasons for them, and their influence on program processes. Developers identified common implementation challenges across health departments and developed implementation tip sheets that addressed common challenges. They also included examples of acceptable adaptations that maintained the basic theory underlying the program.

\section{Developer's Essential Role in Translation}

Program developers are in the best position to describe their intervention and to define intervention core components, clarify fidelity and flexibility, and codify implementation lessons from intervention studies. We note four advantages for developers to apply the heuristic of Three Cs prior to intervention dissemination. First, programs that are easily understandable and well-packaged are more desirable to funders, such as federal agencies and foundations, charged with disseminating EBPs. The National Registry of Evidence-Based Programs and Practices, for example, includes a Dissemination Readiness rating based on whether or not programs are packaged with essential training and implementation materials (SAMHSA, 2015). Increasingly, other registries include basic information on implementation to accompany evidence ratings. 
Second, potential implementers have specific information to select programs that are a good fit with the organization's philosophy, resources, and other programming (Forgatch, Patterson, \& Gerwitz, 2013). Eke and colleagues (2006) point to developers' essential role in describing implementation "as delivered," versus "as designed," to help practitioners prepare for EBP implementation in their local contexts. Because behavioral interventions are often tested within service systems or communities, not laboratories, developers typically identify some implementation challenges during evaluation studies. These useful lessons, however, are often omitted from peer-reviewed outcome papers and may not be integrated in program implementation materials. Implementation challenges in the context of well-resourced studies are likely to be even more pronounced in practice settings where organizations may not be primed for implementation.

Third, concrete guidance on increasing fidelity and making adaptations, as well as examples of good implementation practices, helps operationalize what implementation looks like in practice. In our experience, practitioners begin to internalize a program's theory of change, endorse implementation fidelity, and make adaptations that are consistent with the program's underlying theory when they understand the parameters within which the program works in their setting. Other researchers also have found that practitioners make fewer and better adaptations when they understand the program's underlying theory (Dusenbury et al., 2005; Hansen et al., 2013). Developers' examples of high fidelity, good implementation practices, and explanations of why these examples reflect the program's intent can help practitioners visualize their own implementation and guide future development of examples in other settings.

Fourth, developers can translate the spirit or gestalt of the program into more concrete terms that can be easily understood by practitioners in a variety of settings. Practitioners often encounter settings and circumstances that were not envisioned by developers and have little guidance as to how to modify programs to respond to their unique contexts. The Three Cs, therefore, can communicate general program implementation parameters to help practitioners maintain a program's active ingredients while making necessary adjustments to respond to program participants and settings.

Developers play an essential role in positioning youth and family programs for widespread adoption by translating more conceptual ideas and intentions into concrete terms and examples. The Three Cs is a heuristic to organize recommendations for developers and to provide consistent language and concepts that developers can use to link a program's theory to its components. Although we focused on programs for youth and families, the heuristic could be applied to other topic areas or programs that focus on different populations. Regardless of whether or not developers remain involved in the dissemination of their programs, they serve a critical role in translating EBPs for practical use and widespread adoption. 


\section{References}

Aarons, G. A., Miller, E. A., Green, A. E., Perrott, J. A., \& Bradway, R. (2012). Adaptation happens: A qualitative case study of implementation of The Incredible Years evidence-based parent training programme in a residential substance abuse treatment programme. Journal of Children's Services, 7(4), 233-245.

Backer, T. E. (2002). Finding the balance: Program fidelity and adaptation in substance abuse prevention. A state-of-the-art review. Rockville, MD: Substance Abuse and Mental Health Services Administration (SAMHSA), Center for Substance Abuse Prevention (CSAP).

Backer, T. E., \& Guerra, N. G. (2011). Mobilizing communities to implement evidencebased practices in youth violence prevention: The state of the art. American Journal of Community Psychology, 48(1-2), 31-42.

Blakely, C. H., Mayer, J. P., Gottschalk, R. G., Schmitt, N., Davidson, W. S., \& Roitman, D. B. (1987). The fidelity-adaptation debate: Implications for the implementation of public sector social programs. American Journal of Community Psychology, 15, 253268.

Blase, K., \& Fixsen, D. L. (2013). Core intervention components: Identifying and operationalizing what makes programs work. ASPE Research Brief, Office of Human Services Policy, US Department of Health and Human Services. Retrieved from http://aspe.hhs .gov/hsp/13/KeyIssuesforChildrenYouth/CoreIntervention/rb_CoreIntervention.pdf

Brownson, R. C., Fielding, J. E., \& Maylahn, C. M. (2009). Evidence-based public health: A fundamental concept for public health practice. Annual Review of Public Health, 30, $175-201$.

Center for the Study and Prevention of Violence. (n.d.). Blueprints for healthy youth development. Institute of Behavioral Science, University of Colorado Boulder. Retrieved from http://www.colorado.edu/cspv/blueprints

Centers for Disease Control and Prevention (CDC). (2014). Compendium of evidencebased interventions and best practices for HIV prevention. Division of HIV/AIDS Prevention. Retrieved from http://www.cdc.gov/hiv/prevention/research/compendium

Centers for Disease Control and Prevention (CDC). (2015). The guide to community preventive services: What works to promote health. Retrieved from http://www.the communityguide.org/

Collins, C. B., Edwards, A. E., Jones, P. L., Kay, L., Cox, P. J., \& Puddy, R. W. (2012). A comparison of the interactive systems framework (ISF) for dissemination and implementation and the CDC Division of HIV/AIDS Prevention's research-to-practice model for behavioral interventions. American Journal of Community Psychology, 50, 518-529.

Dane, A. V., \& Schneider, B. H. (1998). Program integrity in primary and early secondary prevention: Are implementation effects out of control? Clinical Psychology Review, 18(1), 23-45.

Davies, P. (1999). What is evidence-based education? British Journal of Educational Studies, 47(2), 108-121.

Durlak, J. A., \& DuPre, E. P. (2008). Implementation matters: A review of research on the influence of implementation on program outcomes and the factors affecting implementation. American Journal of Community Psychology, 41, 327-350.

Dusenbury, L., Brannigan, R., Hansen, W. B., Walsh, J., \& Falco, M. (2005). Quality of implementation: Developing measures crucial to understanding the diffusion of preventive interventions. Health Education Research, 20(3), 308-313.

Eke, A. N., Neumann, M. S., Wilkes, A. L., \& Jones, P. L. (2006). Preparing effective behavioral interventions to be used be prevention providers: The role of researchers during HIV prevention trials. AIDS Education and Prevention, 18(Supplement A), 44-58. 
Fixsen, D. L., Naoom, S. F., Blase, K. A., Friedman, R. M., \& Wallace, F. (2005). Implementation research: A synthesis of the literature (FMHI Publication \#231). Tampa, FL: University of South Florida. Retrieved from http://ctndisseminationlibrary.org/ PDF/nirnmonograph.pdf

Forgatch, S., Patterson, G. R., \& Gerwitz, A. H. (2013). Looking forward: The promise of widespread implementation of parent training programs. Perspectives on Psychological Science, 8(6), 682-694.

Franzen, S., Morrel-Samuels, S., Reischl, T. M., \& Zimmerman, M. A. (2009). Using process evaluation to strengthen intergenerational partnerships in the Youth Empowerment Solutions program. Journal of Prevention E Intervention in the Community, 37(4), 289-301.

Freire, K. E., Perkinson, L., Romney, S., \& Lippy, C. (2015). Triple P implementers' experiences with different parent groups: Adaptation types and reasons. Manuscript in preparation.

Galbraith, J. S., Herbst, J. H., Whittier, D. K., Jones, P. L., Smith, B. D., \& Fisher, H. H. (2011). Taxonomy for strengthening the identification of core elements for evidencebased behavioral interventions for HIV/AIDS prevention. Health Education Research, 26, 872-885.

Glanz, K., Rimer, B., \& Viswanath, K. (Eds.). (2008). Theory, research \& practice in health behavior $\&$ health education. In Health behavior $\&$ health education: Theory, research $\&$ practice (4th ed., pp. 23-40). San Francisco, CA: Jossey-Bass.

Glasgow, R. E., Lichtenstein, E., \& Marcus, A. C. (2002). Why don't we see more translation of health promotion research to practice? Rethinking the efficacy-to-effectiveness transition. American Journal of Public Health, 93(8), 1261-1267.

Halle, T., Metz, A., \& Martinez-Beck, I. (Eds.). (2013). Applying implementation science in early childhood programs and systems. Baltimore, MD: Brookes.

Hansen, W. B., Pankratz, M. M., \& Bishop, D. C. (2014). Differences in observers' and teachers' fidelity assessments. Journal of Primary Prevention, 35, 297-308.

Hansen, W. B., Pankratz, M. M., Dusenbury, L., Giles, S. M., Bishop, D. C., Albritton, J., \& Strack, J. (2013). Styles of adaptation. Health Education, 113(4), 345-363. doi:10.1108/09654281311329268

Jaime, M. C., Stocking, M., Freire, K., Perkinson, L., Ciaravino, S., \& Miller, E. (2015). Prevention advocate as implementer of an athletic-based dating violence prevention program. Manuscript in preparation.

Jones, P. L., Baker, J. L., Gelaude, D., King, W., \& Jemmott, L. (2013). Lessons learned from field-testing a brief behavioral intervention package for African American women at risk for HIV/STDs. Health Promotion Practice, 14(2), 68-73.

Kelly, J. A., Heckman, T. G., Stevenson, L. Y., \& Williams, P. N. (2000). Transfer of research-based HIV prevention interventions to community service providers: Fidelity and adaptation. AIDS Education and Prevention, 12, 87-98.

Kilbourne, A. M., Neumann, M. S., Pincus, H. A., Bauer, M. S., \& Stall, R. (2007). Implementing evidence-based interventions in health care: Application of the replicating effective programs framework. Implementation Science, 2(42). doi:10.1186/17485908-2-42.

Kirby, D., Laris, B. A., \& Rolleri, L. (2006). Sex and HIV education programs for youth: Their impact and important characteristics. Scotts Valley, CA: ETR Associates.

Mazzucchelli, T., \& Sanders, M. (2010). Facilitating practitioner flexibility within an empirically supported intervention: Lessons from a system of parenting support. Clinical Psychology: Science and Practice, 17(3), 238-252.

McGraw, S. A., Sellers, D. E., Johnson, C. C., Stone, E. J., Bachman, K. J., Bebchuk, J., . . $\&$ Edmundson, E. W. (1996). Using process data to explain outcomes. An illustration from the Child and Adolescent Trial for Cardiovascular Health (CATCH). Evaluation Review, 20(3), 291-312. 
McKleroy, V., Galbraith, J. S., Cummings, B., Jones, P., Harshbarger, P., Collins, C., $\&$ The ADAPT Team. (2006). Adapting evidence-based behavioral interventions for new settings and target populations. AIDS Education and Prevention, 18(Suppl A), 59-73.

Miller, E., Tancredi, D. J., McCauley, H. L., Decker, M. R., Virata, M. C., Anderson, H. A.,... Silverman, J. G. (2012). Coaching Boys into Men: A cluster-randomized controlled trial of a dating violence prevention program. Journal of Adolescent Health, 51(5), 431-438.

Miller, E., Tancredi, D. J., McCauley, H. L., Decker, M. R., Virata, M. C., Anderson, H. A., ... Silverman, J. G. (2013). One-year follow-up of a coach-delivered dating violence prevention program: A cluster randomized controlled trial. American Journal of Preventive Medicine, 45(1), 108-112.

Moore, J. E., Bumbarger, B. K., \& Rhoades Cooper, B. L. (2013). Examining adaptations of evidence-based programs in natural contexts. Journal of Primary Prevention, 34(3), 147-161.

Morrel-Samuels, S., Hutchison, P., Perkinson, L., Bostic, B., \& Zimmerman, M. (2014). Selecting, implementing and adapting Youth Empowerment Solutions (YES). Ann Arbor, MI: Authors.

Mowbray, C. T., Holter, M. C., Teague, G. B., \& Bybee, D. (2003). Fidelity criteria: Development, measurement, and validation. American Journal of Evaluation, 24(3), 315-340.

Ozer, E. J., Wanis, M. G., \& Bazell, N. (2010). Diffusion of school-based prevention programs in two urban districts: Adaptations, rationales, and suggestions for change. Prevention Science, 11, 42-55.

Paulsell, D., Del Grosso, P., \& Supplee, L. (2014). Supporting replication and scale-up of evidence-based home visiting programs: Assessing the implementation knowledge base. American Journal of Public Health, 104(9), 1624-1632.

Prinz, R. J., Sanders, M. R., Shapiro, C. J., Whitaker, D. J., \& Lutzker, J. R. (2009). Population-based prevention of child maltreatment: The U.S. Triple P system population trial. Prevention Science, 10(1), 1-12.

Reischl, T. M., Zimmerman, M. A., Morrel-Samuels, S., Franzen, S. P., Faulk, M., Eisman, A. B., \& Roberts, E. (2011). Youth Empowerment Solutions for violence prevention. Adolescent Medicine: State of the Art Reviews, 22(3), 581-600.

Resnicow, K., Soler, R., Braithwaite, R. L., Ahluwalia, J. S., \& Butler, J. (2000). Cultural sensitivity in substance use prevention. Journal of Community Psychology, 28, 271290.

Ringwalt, C. L., Ennett, S., Vincus, A., \& Simons-Rudolph, A. (2004). Students' special needs and problems as reasons for the adaptation of substance abuse prevention curricula in the nation's middle schools. Prevention Science, 5, 197-206.

Rogers, E. (1995). Diffusion of innovation (5th ed.). New York, NY: The Free Press.

Sackett, D. L., Rosenberg, W., Gray, J. A., Haynes, R. B., \& Richardson, W. S. (1996). Evidence based medicine: What it is and what it isn't. British Medical Journal, 312(7023), 71-72.

Sanders, M. R. (1999). Triple P-Positive Parenting Program: Towards an empirically validated multilevel parenting and family support strategy for the prevention of behavior and emotional problems in children. Clinical Child and Family Psychology Review, 2(2), 71-90.

Steckler, A., \& Linnan, L. (2002). Process evaluation for public health interventions and research: An overview. In A. Steckler \& L. Linnan (Eds.), Process evaluation for public health interventions and research (pp. 1-23). San Francisco, CA: Jossey-Bass.

Substance Abuse and Mental Health Services Administration (SAMHSA). (2015). SAMHSA's national registry of evidence-based programs and practices (NREPP). Retrieved from http://www.nrepp.samhsa.gov/AboutNREPP.aspx 
U.S. Department of Health and Human Services (HHS) Office of Adolescent Health. (2015). Teen pregnancy prevention resource center: Evidence-based programs. Retrieved from http://www.hhs.gov/ash/oah/oah-initiatives/teen_pregnancy/db

Wandersman, A., Duffy, J., Flaspohler, P., Noonan, R., Lubell, K., Stillman, L., .. Saul, J. (2008). Bridging the gap between prevention research and practice: The interactive systems framework for dissemination and implementation. American Journal of Community Psychology, 41(3-4), 171-181.

Wilkes, A. L., Jones, P. L., Morales-Reid, B., Ramos, B., Vega, M. Y., Scholes, D., ... Polk, L. (2014). Lessons learned while preparing a tailored, self-help, technology-driven intervention for national dissemination. AIDS Education \& Prevention, 26(4), 281295.

Wilson, K. M., Brady, T. J., \& Lesesne, C., on behalf of the NCCDPHP Work Group on Translation. (2011). An organizing framework for translation in public health: The Knowledge to Action Framework. Prevention of Chronic Disease, 8(2), A46.

Woolf, S. H. (2008). The meaning of translational research and why it matters. The Journal of the American Medical Association, 299(2), 211-213.

Zimmerman, M. A., Stewart, S. E., Morrel-Samuels, S., Franzen, S., \& Reischl, T. M. (2011). Youth Empowerment Solutions for peaceful communities: Combining theory and practice in a community-level violence prevention curriculum. Health Promotion Practice, 12(3), 425-439.

KIMBERLEY E. FREIRE works in the Division of Violence Prevention at the Centers for Disease Control \& Prevention.

LEAH PERKINSON works for the CDC Foundation in the Division of Violence Prevention at the Centers for Disease Control \& Prevention.

SuSAN MORREL-SAMUELS is managing director for the Prevention Research Center of Michigan and the Michigan Youth Violence Prevention Center at the University of Michigan.

MARC A. ZIMMERMAN is a professor in the Department of Health Behavior \& Health Education at the University of Michigan School of Public Health. 